\title{
OPTIMAL REACTIVE POWER DISPATCH WITH SERIES AND SHUNT FACTS DEVICES USING SINE COSINE ALGORITHM
}

\author{
R. Ravisekar \\ Research Scholar, Electrical and Electronics Engineering Dept. \\ Bharath Institute of Higher Education and Research Chennai, India

\section{Dr. K. Srinivasan} \\ Professor and Head Electrical and Electronics Engineering Dept. \\ Tagore Engineering. College, Chennai, India
}

\begin{abstract}
Management of reactive power resources is essential for the secure and stable functioning of power systems in the standpoint of voltage stability. The principal aim of optimal reactive power dispatch (ORPD) is to detect the settings of control variables such as the voltage rating of generators, reactive power injection of VAR compensators and tap ratios of the tap setting transformers in order to decrease the grid congestion with one or more objective of minimizing the active power loss for a fixed economic power schedule while meeting a given lot of constraints. In this paper, Flexible AC Transmission System (FACTS) controllers named as Unified Power Flow Controller (UPFC) is added with conventional ORPD problem for active power loss minimization with voltage profile improvement. Also, this paper demonstrates the application of sine cosine algorithm (SCA) to discover the optimal solution of ORPD (with UPFC) of power system with different test systems (IEEE 57-bus and IEEE 118bus) with distinct cases such as minimization of active power losses and improvement of voltage profile. Simulation results show the high quality and accuracy of the proposed algorithm, and considering the quality of the solution obtained, the proposed algorithm appears to be efficient and robust to solve the ORPD problem comparing with existing literatures.
\end{abstract}

Keywords: Optimal reactive power dispatch, Active power Loss reduction, Improvement of voltage profile, FACTS devices, Sine cosine algorithm, Whale optimization algorithm, Ant lion optimizer

Cite this Article: R. Ravisekar and Dr. K. Srinivasan, Optimal Reactive Power Dispatch with Series and Shunt Facts Devices using Sine Cosine Algorithm, International Journal of Advanced Research in Engineering and Technology (IJARET), 11 (1), 2020, pp 90-109.

http://iaeme.com/Home/issue/IJARET?Volume $=11 \&$ Issue $=1$ 


\section{INTRODUCTION}

In the last few decades, optimal reactive power dispatch (ORPD) has received great attention and it has become a tool for improving economy and security of power system operation. The ORPD, which is a non-linear, non-convex and non-differentiable optimisation problem, aims at minimising the objective functions such as voltage stability and system real power losses via adjustments of control parameters like generators voltages, switchable volt-ampere reactive (VAR) sources, transformer tap settings etc. in a power system while satisfying equality and inequality constraints [1-3].

According to the literature, mathematical algorithms such as Decomposition method, Newton approach, non-linear programming, interior point, Jacobian matrix etc. have been used for ORPD solutions initially [4-7]. These algorithms optimise the objective function by linearising it. Since the ORPD problem has local optima more than one, it is a non-linear and multi-modal optimisation problem. Hence, it is so hard to find the global optimum using mathematical algorithms in solution of the ORPD problem. Nevertheless, there are some disadvantages special to the algorithms such as insecure convergence and algorithmic complexity. For these reasons, researchers were developed heuristic and meta heuristic based algorithms for solving the ORPD problem was presented in Table. 1.

Table 1 Summary of the proposed algorithms for solution of ORPD problem in literature

\begin{tabular}{|c|c|c|c|}
\hline Reference & Approach & Objective & Test System \\
\hline Yan et al. (2004) [8] & IEP & Pow & $\begin{array}{l}\text { IEEE 118-bus system and a } \\
\text { realistic power system in } \\
\text { Western China }\end{array}$ \\
\hline Zhao et al. (2005) [9] & MAPSO & Power loss & IEEE 30-bus and IEEE 118-bus \\
\hline $\begin{array}{l}\text { Varadarajan and Swarup } \\
(2008)[10]\end{array}$ & $\mathrm{DE}$ & Power loss & $\begin{array}{l}\text { IEEE 14, IEEE 30, and IEEE } \\
\text { 118-Bus }\end{array}$ \\
\hline Ying Li et al. (2009) [11] & DPSO & $\begin{array}{l}\text { power loss and } \\
\text { the costs of adjusting the } \\
\text { control devices }\end{array}$ & IEEE 30-bus \\
\hline Chaohua et al. (2009) [12] & SOA & Power loss & IEEE 57-bus and IEEE 118-bus \\
\hline $\begin{array}{l}\text { Mahadevan and Kannan } \\
\text { (2010) [13] }\end{array}$ & CLPSO & Power loss and voltage profile & IEEE 30-bus and IEEE 118-bus \\
\hline $\begin{array}{c}\text { Xuexia Zhang et al., (2010) } \\
{[14]}\end{array}$ & DMSDE & Power loss & $\begin{array}{c}\text { IEEE 30-bus, IEEE 57-bus and } \\
\text { IEEE 118-bus }\end{array}$ \\
\hline $\begin{array}{c}\text { Khazali and Kalantar (2011) } \\
{[15]}\end{array}$ & HSA & Power loss and voltage profile & IEEE 30-bus and IEEE 57-bus \\
\hline S. Jeyadevi et al. (2011) [16] & MNSGA-II & $\begin{array}{l}\text { Power loss and voltage } \\
\text { stability } \\
\end{array}$ & IEEE 30-bus and IEEE 118-bus \\
\hline Roy et a & $\mathrm{BBO}$ & Power loss and voltage profile & IEEE 30-bus and IEEE 118-bus \\
\hline Xu et al. (2012) [18] & MASRL & Pov & $\begin{array}{l}\text { Ward-Hale 6-bus, IEEE 30-bus } \\
\text { and IEEE 162-bus }\end{array}$ \\
\hline S. Duman et al. (2012) [19] & GSA & $\begin{array}{c}\text { Power loss, voltage profile, } \\
\text { and voltage stability }\end{array}$ & $\begin{array}{c}\text { IEEE 30-bus, IEEE 57-bus and } \\
\text { IEEE 118-bus }\end{array}$ \\
\hline $\begin{array}{l}\text { R. Mallipeddi et al. (2012) } \\
{[20]}\end{array}$ & HDE & Power loss and voltage profile & $\begin{array}{l}\text { IEEE 30-bus, IEEE57-bus and } \\
\text { IEEE 118-bus }\end{array}$ \\
\hline $\begin{array}{c}\text { Barun Mandal and Provas } \\
\text { Kumar Roy (2013) [21] }\end{array}$ & QOTLBO & $\begin{array}{l}\text { Power loss, voltage profile, } \\
\text { and voltage stability }\end{array}$ & IEEE 30-bus and IEEE 118-bus \\
\hline $\begin{array}{c}\text { Amit Saraswat and } \\
\text { AshishSaini (2013) [22] }\end{array}$ & HFMOEA & $\begin{array}{l}\text { Power loss and voltage } \\
\text { stability }\end{array}$ & IEEE24-busRTS \\
\hline $\begin{array}{l}\text { Mojtaba Ghasemi et al. } \\
\text { (2014) [23] }\end{array}$ & $\begin{array}{l}\text { HMICA- } \\
\text { IWO }\end{array}$ & Power loss & $\begin{array}{c}\text { IEEE 30-bus, IEEE 57-bus and } \\
\text { IEEE 118-bus }\end{array}$ \\
\hline Binod Shaw et al. (2014) [24] & OGSA & $\begin{array}{c}\text { Power loss, voltage profile, } \\
\text { and voltage stability }\end{array}$ & $\begin{array}{c}\text { IEEE 30-bus, IEEE 57-bus and } \\
\text { IEEE 118-bus }\end{array}$ \\
\hline Abhishek Rajan and T. & HFA & Power loss and voltage & IEEE 30-bus and IEEE 118-bus \\
\hline
\end{tabular}




\begin{tabular}{|c|c|c|c|}
\hline Malakar (2015) [25] & & deviation & \\
\hline $\begin{array}{l}\text { Mojtaba Ghasemi et al. } \\
\text { (2015) [26] }\end{array}$ & MGBTLBO & Power loss & IEEE 14-bus and IEEE30-bus \\
\hline $\begin{array}{l}\text { Mehdi Mehdinejad et al. } \\
\text { (2016) [27] }\end{array}$ & ICA-PSO & $\begin{array}{l}\text { Power loss and voltage } \\
\text { deviation }\end{array}$ & IEEE57-bus and IEEE 118-bus \\
\hline $\begin{array}{c}\text { kuppamuthu sivalingam et al. } \\
\text { (2017) [28] }\end{array}$ & HABC & Power loss & $\begin{array}{l}\text { IEEE 6-bus, IEEE14-bus, and } \\
\text { IEEE 30-bus }\end{array}$ \\
\hline $\begin{array}{l}\text { Kasem Nuaekaew et al. } \\
\text { (2017) [29] }\end{array}$ & 2ArchMGWO & Power loss and voltage profile & $\begin{array}{c}\text { IEEE 30-bus, IEEE 57-bus and } \\
\text { IEEE 118-bus }\end{array}$ \\
\hline $\begin{array}{c}\text { Xiaoshun Zhang et al. (2017) } \\
{[30]}\end{array}$ & ABO-TRL & $\begin{array}{l}\text { Power loss and voltage } \\
\text { deviation }\end{array}$ & IEEE118-bus and IEEE 300-bus \\
\hline $\begin{array}{l}\text { Khaled ben oualid Medania } \\
\text { (2018) [31] }\end{array}$ & WOA & Power loss & $\begin{array}{l}\text { IEEE 14-bus, IEEE 30-bus, } \\
\text { Algerian electric 114-bus }\end{array}$ \\
\hline $\begin{array}{l}\text { SK. Mahammad Shareefa and } \\
\text { R. Srinivasa Rao (2018) [32] }\end{array}$ & $\mathrm{ABC}-\mathrm{FF}$ & $\begin{array}{l}\text { Power loss and voltage } \\
\text { stability } \\
\end{array}$ & IEEE 14 and IEEE 39 bus \\
\hline $\begin{array}{c}\text { Hotaka yoshida and } \\
\text { Yoshikazu fukuyama (2018) } \\
{[33]}\end{array}$ & DEEPSO & Power loss & $\begin{array}{c}\text { IEEE 30-bus, IEEE 57-bus and } \\
\text { IEEE 118-bus }\end{array}$ \\
\hline
\end{tabular}

Recently, Sine Cosine Algorithm (SCA) is a new meta-heuristic search algorithm. It has been proposed by Seyedali Mirjalili in 2016. It has been reported in [34] that the SCA has a lot of advantages and it is different from the other meta heuristic algorithms like GSA etc. These are expressed in detail in [34]. Moreover, in [34], SCA has been examined on 19 different standard benchmark functions and aircraft design problem compared with other meta heuristic algorithms such as Firefly Algorithm (FA), Bat Algorithm (BA), Flower Pollination Algorithm (FPA) and Gravitational Search Algorithm (GSA).

It was found that the results obtained by SCA in most cases provide superior results and in all cases are comparable with others. The most substantial feature of the SCA is that creating multiple initial random candidate solutions and requires them to fluctuate outwards or towards the best solution using a mathematical model based on sine and cosine functions. Several random and adaptive variables also are integrated to this algorithm to emphasize exploration and exploitation of the search space in different milestones of optimization.

Continuous and fast improvement of power electronics technology has made FACTS as a promising concept for power system applications during the last decade [35,36]. The use of FACTS controllers provides a flexible controlling of power flow along the transmission lines. It can reduce the flows of heavily loaded lines, maintain the bus voltages at desired levels, and improve the stability of the power network. The UPFC [36-38] is the most versatile FACTS controller envisaged so far. It can not only perform the functions of the STATCOM, TCSC and the phase angle regulator but also provides additional flexibility by combining some of the functions of the above controllers. The UPFC can provide simultaneous control of all basic power system parameters. It can fulfill functions of reactive shunt compensation, series compensation and phase shifting meeting multiple control objectives. From a functional perspective, the objectives are met by applying a boosting transformer injected voltage and an exciting transformer reactive current. The injected voltage is inserted by a series transformer.

In order to evaluate the proposed algorithm with UPFC, it was tested on IEEE 57-bus and 118-bus test systems with different objective functions that reflect active power losses and voltage profile improvement, and results obtained from SCA are compared with those reported in the literature.

\section{POWER FLOW MODEL FOR FACTS DEVICES}

FACTS devices are the power electronics based solid state converters that can be integrated in power system as shunt and series connected devices. The series controllers build up voltage in series with the line and the shunt controllers injects current into the system. The combined 
series and shunt controllers inject both voltage and current into the system. Shunt compensation are used to provide reactive power compensation and series compensator is used to enhance the power flow.

Gyugyi in 1991 proposed the Unified Power Flow Controller. It is the most versatile and complex power electronic device and member of third generation FACTS Controller introduced to control the power flow and voltage in the power systems. It is designed by combining the features of second-generation FACTS controllers - Series Synchronous Compensator (SSSC) and Static Synchronous Compensator (STATCOM). It has the ability to control active and reactive power flow of a transmission line simultaneously in addition to controlling all the transmission parameters (voltage, impedance and phase angle) affecting the power flow in a transmission line [35-38].

\subsection{Modeling of UPFC}

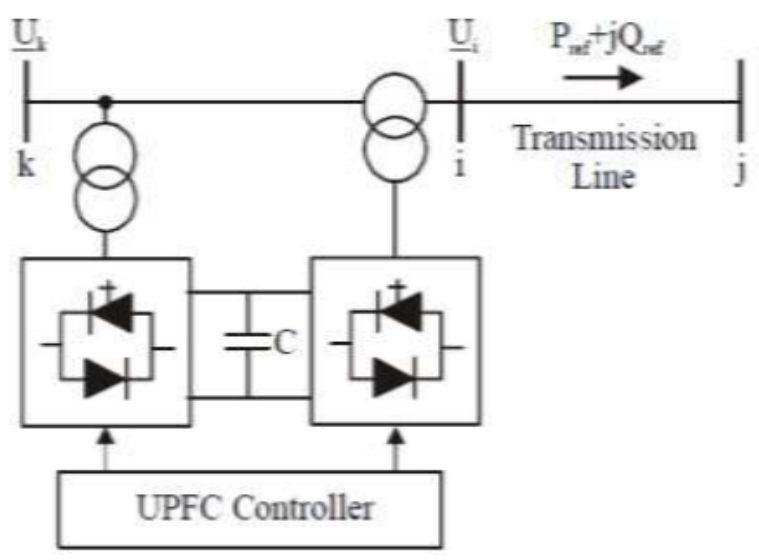

Figure.1 UPFC model

The above figure 1 taken from reference [36] gives a clear description about how UPFC controller connected to a transmission line. It consists of two back-to-back self-commutated voltage source converters - one converter at the sending end is connected in shunt as shunt converter and the other converter connected in between sending and receiving end bus in series as series converter. One end of the both the converters are connected to a power system through an appropriate transformer and other end connected with a common DC capacitor link [36].

\subsection{Operation of UPFC}

This arrangement of UPFC ideally works as an ideal ac to dc power converter in which real power can freely flow in either direction between ac terminals of the two converters and each converter can independently generate or absorb reactive power at its own AC output terminal. The main functionality of UPFC provided by shunt converter by injecting an ac voltage considered as a synchronous ac voltage source with controllable phase angle and magnitude in series with the line. The transmission line current flowing through this voltage source results in real and reactive power exchange between it and the AC transmission system. The inverter converts the real power exchanged at ac terminals into dc power which appears at the dc link as positive or negative real power demand [37]. 


\subsection{Operation of two converters:}

\subsubsection{Series Converter Operation}

In the series converter, the voltage injected can be determined in different modes of operation: direct voltage injection mode, phase angle shift emulation mode, Line impedance emulation mode and automatic power flow control mode. Although there are different operating modes to obtain the voltage, usually the series converter operates in automatic power flow control mode where the reference input values of $\mathrm{P}$ and $\mathrm{Q}$ maintain on the transmission line despite the system changes [38].

\subsubsection{Shunt Converter Operation}

The shunt converter operated in such a way to demand the de terminal power (positive or negative) from the line keeping the voltage across the storage capacitor Vdc constant. Shunt converter operates in two modes: VAR Control mode and Automatic Voltage Control mode. Typically, Shunt converter in UPFC operates in Automatic voltage control mode [38].

\subsection{Equivalent Circuit Operation of UPFC}

As shown in Fig 2, the two-voltage source converters of UPFC can modeled as two ideal voltage sources one connected in series and other in shunt between the two buses. The output of series voltage magnitude $V_{s e}$ controlled between the limits $V_{s e \max } \leq V_{s e} \leq V_{\text {semin }}$ and the angle $\theta_{s e}$ between the limits $0 \leq \theta_{s e} \leq 2 \Pi$ respectively. The shunt voltage magnitude $V_{s h}$ controlled between the limits $V_{s h \max } \leq V_{s h} \leq V_{s h \text { min }}$ and the angle between $0 \leq \theta_{s h} \leq 2 \Pi$ respectively. $Z_{s e}$ and $Z_{s h}$ are considered as the impedances of the two transformers one connected in series and other in shunt between the transmission line and the UPFC as shown in the Fig 2 which is the UPFC equivalent circuit [36].

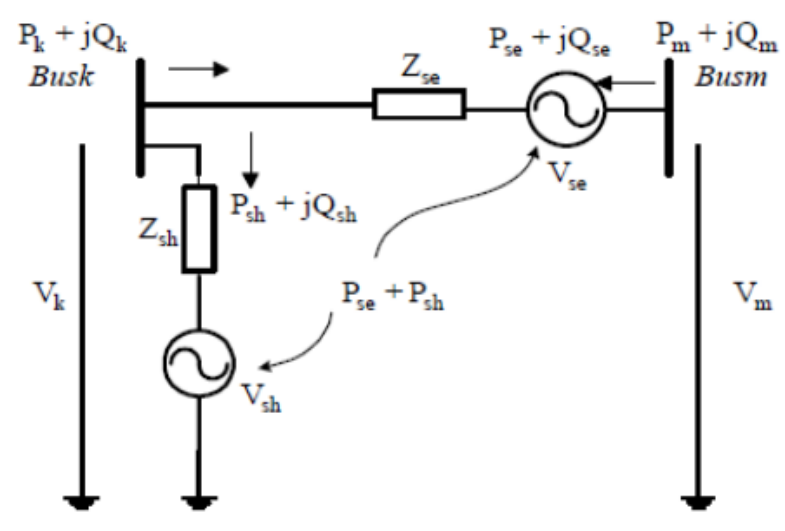

Figure 2. Equivalent circuit of UPFC

The ideal series and voltage source from the Fig 4.2 can written as

$$
\begin{gathered}
V_{s e}=V_{s e}\left(\cos \theta_{s e}+j \sin \theta_{s e}\right) \\
V_{s h}=V_{s h}\left(\cos \theta_{s h}+j \sin \theta_{s h}\right)
\end{gathered}
$$

The magnitude and the angle of the converter output voltage used to control the power flow mode and voltage at the nodes as follows:

- The bus voltage magnitude can be controlled by the injected a series voltage $V_{s e}$ in phase or anti-phase. 
Optimal Reactive Power Dispatch with Series and Shunt Facts Devices using Sine Cosine Algorithm

- Power flow as a series reactive compensation controlled by injecting a series voltage $V_{s e}^{\prime}$ in quadrature to the line current.

- Power flow as phase shifter controlled by injecting a series voltage of magnitude $V{ }_{s e}$ in quadrature to node voltage $\theta_{m}$ [38].

\subsubsection{UPFC power Equations}

Based on the equivalent circuit as shown in Fig 4.2, the active and reactive power equations can be written as follows [27, 7]:

At node k:

$$
\begin{aligned}
& P_{k}=V_{k}^{2} G_{k k}+V_{k} V_{m}\left(G_{k m} \cos \left(\theta_{k}-\theta_{m}\right)+B_{k m} \sin \left(\theta_{k}-\theta_{m}\right)\right) \\
& +V_{k} V \operatorname{se}\left(G_{k m} \cos \left(\theta_{k}-\theta_{s e}\right)+B_{k m} \sin \left(\theta_{k}-\theta_{s e}\right)\right) \\
& +V_{k} V_{s h}\left(G_{s h} \cos \left(\theta_{k}-\theta_{s h}\right)+B_{s h} \sin \left(\theta_{k}-\theta_{s h}\right)\right) \\
& Q_{k}=-V_{k}^{2} B_{k k}+V_{k} V_{m}\left(G_{k m} \sin \left(\theta_{k}-\theta_{m}\right)-B_{k m} \cos \left(\theta_{k}-\theta_{m}\right)\right) \\
& +V_{k} V_{s e}\left(G_{k m} \sin \left(\theta_{k}-\theta_{s e}\right)-B_{k m} \cos \left(\theta_{k}-\theta_{s e}\right)\right) \\
& +V_{k} V_{s h}\left(G_{s h} \sin \left(\theta_{k}-\theta_{s h}\right)-B_{s h} \cos \left(\theta_{k}-\theta_{s h}\right)\right)
\end{aligned}
$$

At node m:

$$
\begin{aligned}
& P_{m}=V_{m}^{2} G_{m m}+V_{m} V_{k}\left(G_{m k} \cos \left(\theta_{m}-\theta_{k}\right)+B_{m k} \sin \left(\theta_{m}-\theta_{k}\right)\right) \\
& +V_{m} V_{s e}\left(G_{m m} \cos \left(\theta_{m}-\theta_{s e}\right)+B_{m m} \sin \left(\theta_{m}-\theta_{s e}\right)\right) \\
& Q_{m}=-V_{m}^{2} B_{m m}+V_{m} V_{k}\left(G_{m k} \sin \left(\theta_{m}-\theta_{k}\right)-B_{m k} \cos \left(\theta_{m}-\theta_{k}\right)\right) \\
& +V_{m} V_{s h}\left(G_{m m} \sin \left(\theta_{m}-\theta_{s e}\right)-B_{m m} \cos \left(\theta_{m}-\theta_{s e}\right)\right)
\end{aligned}
$$

Series converter:

$$
\begin{aligned}
& P_{s e}=V_{s e}^{2} G_{m m}+V_{s e} V_{k}\left(G_{k m} \cos \left(\theta_{s e}-\theta_{k}\right)+B_{k m} \sin \left(\theta_{s e}-\theta_{k}\right)\right) \\
& +V_{s e} V_{m}\left(G_{m m} \cos \left(\theta_{s e}-\theta_{k}\right)+B_{m m} \sin \left(\theta_{s e}-\theta_{m}\right)\right. \\
& Q_{s e}=-V_{s e}^{2} B_{m m}+V_{s e} V_{k}\left(G_{k m} \sin \left(\theta_{s e}-\theta_{k}\right)-B_{k m} \cos \left(\theta_{s e}-\theta_{k}\right)\right) \\
& +V_{s e} V_{m}\left(G_{m m} \sin \left(\theta_{s e}-\theta_{m}\right)-B_{m m} \cos \left(\theta_{s e}-\theta_{m}\right)\right)
\end{aligned}
$$

Shunt converter:

$$
\begin{gathered}
P_{s h}=-V_{s h}^{2} G_{s h}+V_{s h} V_{k}\left(G_{s h} \cos \left(\theta_{s h}-\theta_{k}\right)+B_{s h} \sin \left(\theta_{s h}-\theta_{k}\right)\right. \\
Q_{s h}=V_{s h}^{2} B_{s h}+V_{s h} V_{k}\left(G_{s h} \sin \left(\theta_{s h}-\theta_{k}\right)-B_{s h} \cos \left(\theta_{s h}-\theta_{k}\right)\right)
\end{gathered}
$$

Where

$$
\begin{gathered}
Y_{k k}=G_{k k}+j B_{k k}=Z_{s e}^{-1}+Z_{s h}^{-1} \\
Y_{m m}=G_{m m}+j B_{m m}=Z_{s e}^{-1} \\
Y_{k m}=Y_{m k}=G_{k m}+j B_{k m}=-Z_{s e}^{-1} \\
Y_{s h}=G_{s h}+j B_{s h}=-Z_{s h}^{-1}
\end{gathered}
$$


Assuming a free converter loss operation, the active power supplied to the shunt converter $P_{s h}$ equals to the active power demanded by the series converter $P_{s e}[36]$.

$$
P_{s e}+P_{s h}=0
$$

Furthermore, if the coupling transformers are assumed to contain no resistance then the active power at bus $\mathrm{k}$ matches the active power at bus $\mathrm{m}$; that is,

$$
P_{s h}+P_{s e}=P_{k}+P_{m}=0
$$

The UPFC power equations linearised and combined with the equations of the $\mathrm{AC}$ transmission network. For the cases when the UPFC controls the following parameters:

- voltage magnitude at the shunt converter terminal

- active power flow from bus $\mathrm{m}$ to bus $\mathrm{k}$ and

- reactive power injected at bus $\mathrm{m}$, and taking bus $\mathrm{m}$ to be PQ bus.

\section{PROBLEM FORMULATION}

The solution of the optimal reactive power dispatch (ORPD) problem involves the optimization of the non-linear objective function with non-linear system constraints.

\subsection{Minimization of real power losses}

The principal target of multi objective optimization is to minimize the active power loss in the transmission network, which is specified as follows [8-34]:

$$
F_{1}=\sum_{k=1}^{N T} P_{l o s s, \mathrm{k}}=\sum_{k=1}^{N T} G_{k}\left(V_{i}^{2}+V_{j}^{2}\right)-2 V_{i} V_{j} \cos \left(\delta_{i}-\delta_{j}\right)
$$

where $N T$ is the number of transmission lines, $G_{k}$ is the conductance of the $k^{\text {th }}$ line, $V_{i}$ and $V_{j}$ are the voltage magnitude of the $i^{\text {th }}$ and $j^{\text {th }}$ buses, and $\delta_{i}$ and $\delta_{j}$ are the voltage phase angles of $i^{\text {th }}$ and $j^{\text {th }}$ buses.

\subsection{Improvement of Voltage Profile}

Another aim of this problem is to improve the voltage profile which is formulated mathematically as follows [13,17,19-21,24,29],

$$
F_{2}=\sum_{i=1}^{N P Q}\left|V_{\mathrm{i}, \mathrm{spec}}-V_{i}\right|
$$

where $N P Q$ is the number of load buses in the power system and $\mathrm{V} i$ is the reference value of the voltage magnitude of the $i^{\text {th }}$ bus which is equal to $1.0(\mathrm{pu})$

By combining the Eq.(16) and Eq. (17) leads to the main objective function as follows:

$$
F_{o b j}=F_{1}+F_{2}=\left(\sum_{k=1}^{N T} P_{l o s s, \mathrm{k}}\right)+\left(\sum_{i=1}^{N P Q}\left|V_{\mathrm{i}, \mathrm{spec}}-V_{i}\right|\right)
$$




\subsection{Constraints}

\subsubsection{Equality Constraints}

These constraints, which are load flow equations, are described as follows

$$
\begin{gathered}
P_{G i}-P_{D i}-\sum_{j \in N B} V_{i} V_{j}\left(G_{i j} \cos \delta_{i j}+B_{i j} \sin \delta_{i j}\right)=0 \\
Q_{G i}-Q_{D i}-\sum_{j \in N B} V_{i} V_{j}\left(G_{i j} \sin \delta_{i j}+B_{i j} \cos \delta_{i j}\right)=0
\end{gathered}
$$

where $N B$ is the number of buses, $P_{G i}$ and $Q_{G i}$ are generated active and reactive power, $P_{D i}$ and $Q_{D i}$ are load active and reactive power, $G_{i j}$ is the transfer conductance and $B_{i j}$ is the transfer susceptance between $i^{\text {th }}$ bus and $j^{\text {th }}$ bus, respectively.

\subsubsection{Inequality Constraints}

\section{Generator Constraints}

Generator voltages, reactive outputs ought to be restricted by their lower and upper limits as follows

$$
\begin{array}{ll}
Q_{G, i}^{\min } \leq Q_{G, i} \leq Q_{G, i}^{\max } & \mathrm{i} \in N G \\
V_{G, i}^{\min } \leq V_{G, i} \leq V_{G, i}^{\max } & \mathrm{i} \in N G
\end{array}
$$

\section{Transformer Constraints}

Transformer tap setting are bounded as follows:

$$
T_{i}^{\min } \leq T_{i} \leq T_{i}^{\max } \quad \mathrm{i} \in \text { No of transformers }
$$

\section{Shunt VAr Compensator Constraints}

Shunt VAR compensators ought to be restricted by their lower and upper limits as follows

$$
Q_{\mathrm{C}, i}^{\min } \leq Q_{\mathrm{C}, i} \leq Q_{\mathrm{C}, i}^{\max } \quad \mathrm{i} \in N C
$$

\section{Security Constraints}

These include the constraints of voltages at load buses and transmission line loading as follows:

$$
\begin{array}{lc}
V_{\mathrm{L}, i}^{\min } \leq V_{\mathrm{L}, i} \leq V_{\mathrm{L}, i}^{\max } & \mathrm{i} \in N P Q \\
S_{\mathrm{L}, j} \leq S_{\mathrm{L} j}^{\max } & \mathrm{i} \in N T
\end{array}
$$

Eq. (18) and Eq. (19) are changed to the following form using penalty terms to the objective function:

$$
F_{\text {new }}=F_{o b j}+\lambda_{V} \sum_{i=1}^{N P Q}\left(V_{i}-V_{i}^{\mathrm{lim}}\right)^{2}+\lambda_{Q} \sum_{i=1}^{N G}\left(Q_{G, i}-Q_{G, i}^{\mathrm{lim}}\right)^{2}
$$

$x^{\lim }$ is the limit value of the dependent variable $x=\left(V_{i}\right.$ and $\left.Q_{G}\right)$ and given as:

$$
x^{\lim }=x^{\max } \text { if } x>x^{\max } \text {, and } x^{\lim }=x^{\min } \text { if } x<x^{\min }
$$

Where $\lambda_{V}$ and $\lambda_{2}$ are the weighting factors to enhance the objective function.

\section{SINE COSINE OPTIMIZATION ALGORITHM}

Irrespective of the differences between algorithms in the area of stochastic population-based optimization, the green is the variance of the optimization process to two phases: exploration versus exploitation. In the late phase, an optimization algorithm combines the random 
solutions in the set of solutions abruptly with a high rate of randomness to find the bright regions of the search space. In the exploitation phase, however, there are gradual changes in the random solutions, and random variations are considerably less than those in the exploration phase.

In this SCA [35], the following position updating equations is proposed for both stages:

$$
\begin{aligned}
& X_{i}^{t+1}=X_{i}^{t}+r_{1} \times \sin \left(r_{2}\right) \times\left\|r_{3} P_{i}^{t}-X_{i}^{t}\right\| \\
& X_{i}^{t+1}=X_{i}^{t}+r_{1} \times \cos \left(r_{2}\right) \times\left\|r_{3} P_{i}^{t}-X_{i}^{t}\right\|
\end{aligned}
$$

where $X_{i}^{t}$ is the position of the current solution in $i^{\text {-th }}$ dimension at $t^{\text {th }}$ iteration, $r_{1} / r_{2} / r_{3}$ are random numbers, $P_{i}$ is position of the destination point in $i^{- \text {th }}$ dimension, and $\|$ indicates the absolute value.

By combining the Eq. (28) and Eq. (29), it will be used as,

$$
X_{i}^{t+1}= \begin{cases}X_{i}^{t}+r_{1} \times \sin \left(r_{2}\right) \times\left\|r_{3} P_{i}^{t}-X_{i}^{t}\right\| & r_{4}<0.5 \\ X_{i}^{t}+r_{1} \times \cos \left(r_{2}\right) \times\left\|r_{3} P_{i}^{t}-X_{i}^{t}\right\| & r_{4} \geq 0.5\end{cases}
$$

where $r_{4}$ is a random number in $[0,1]$.

From the Eq. (28), there are four main parameters in the SCA: $r_{1}, r_{2}, r_{3}$ and $r_{4}$.

- The parameter $r_{l}$ dictates the next position's region (or motion direction) which could be either in the space between the solution and destination or outside it.

- The parameter $r_{2}$ defines how far the trend should be towards or outwards the destination.

- The parameter $r_{3}$ brings a random weight for the destination in order to stochastically emphasize $\left(r_{3}>1\right)$ or deem- phases $\left(r_{3}<1\right)$ the effect of destination in defining the space.

- Lastly, the parameter $\mathrm{r} 4$ equally switches between the sin and cosine components in Eq. (27).

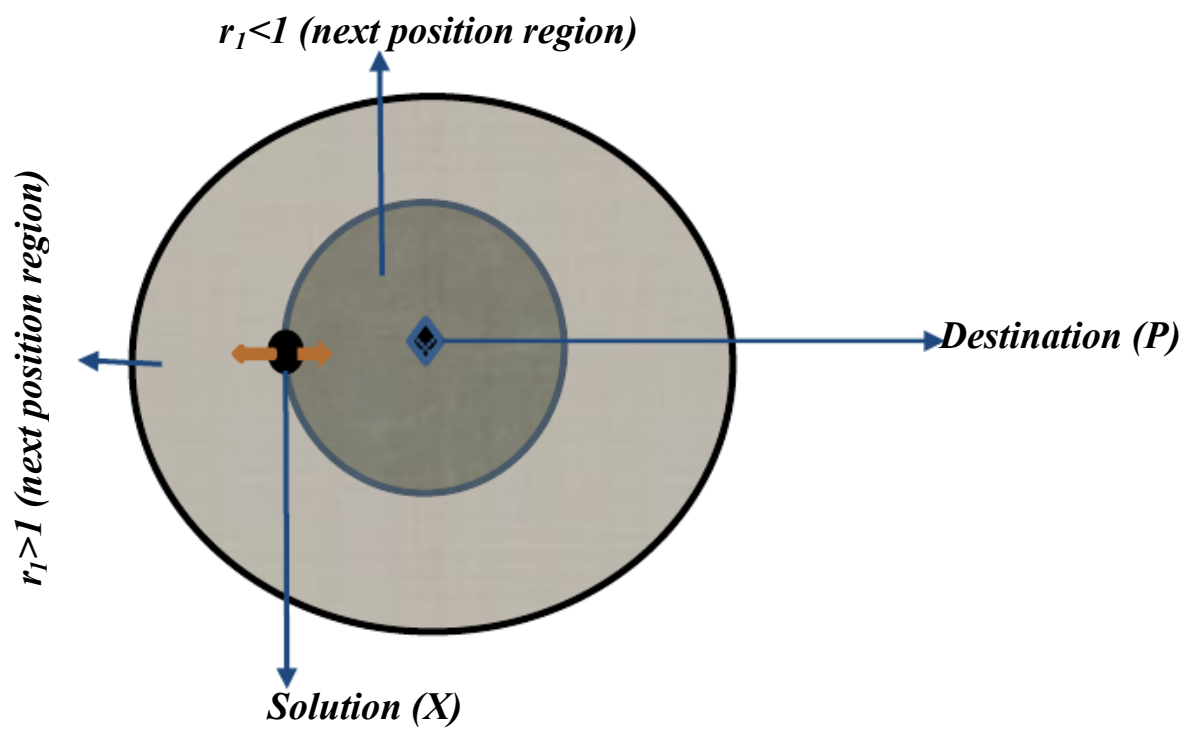

Figure. 3. Properties of Sine and Cosine on the next position

The effects of Sine and Cosine on Eqs. (28) and (29) are illustrated in Fig. 3. This figure shows that how the proposed equations define, a space between two solutions in the search 
space. It should be mentioned that this equality can be stretched to higher dimensions, although a two-dimensional example is exemplified in Fig. 3. The cyclic form of sin and cosine function allows a solution to be re-positioned around another solution. This can guarantee exploitation of the space defined between two answers. For researching the search space, the solutions should be able to seek outside the space between their corresponding destinations as well. This can be accomplished by shifting the orbit of the sine and cosine functions. A conceptual model of the effects of the sine and cosine functions with the range in $[-2,2]$ is illustrated in the Fig. 4 . This copy establishes how fluctuating the range of sine and cosine functions requires a solution to update its position out of entries or in the space between itself and another solution. The random location either at bottom or outside is achieved by specifying a random number for $r_{2}$ in $[0,2 \pi]$ in Eq. (30). Thus, this mechanism guarantees exploration and exploitation of the search space respectively.

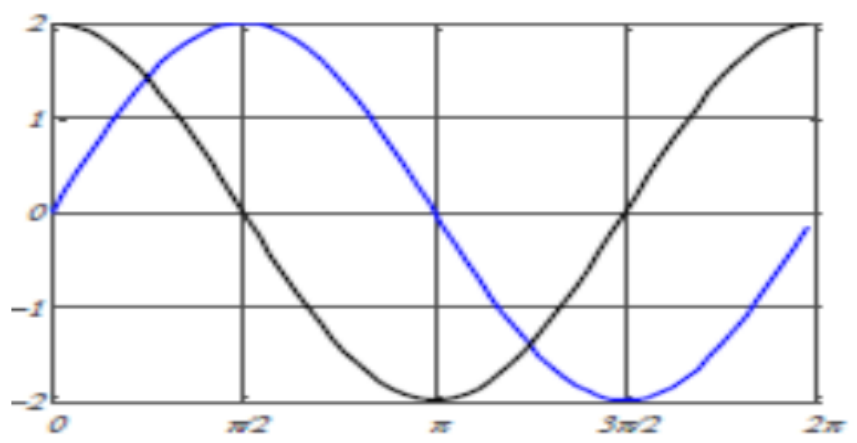

Figure 4. Sine and cosine with range of $[-2,2]$

The following equation is used to update the value of $r_{1}$ in Eqs. (27) to (30),

$$
r_{1}=a-t \frac{a}{T}
$$

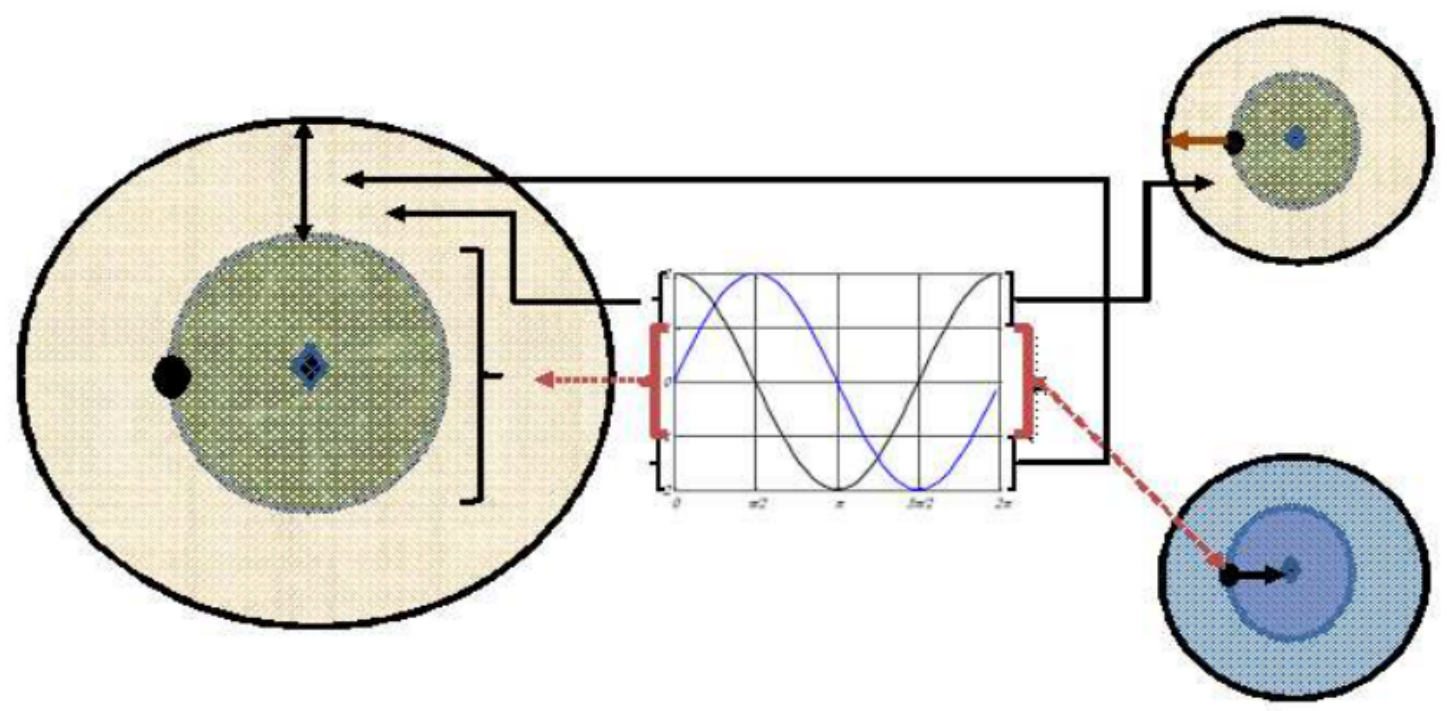

Figure 5. Sine and cosine with the range in [-2,2] allow a solution to go around (inside the space between them) or beyond (outside the space between them) the destination

where $t$ is the current iteration, $T$ is the maximum number of iterations, and $a$ is a constant.

From the explanation, equation decreases the range of sine and cosine functions over the course of iterations are shown in Fig. 5. 


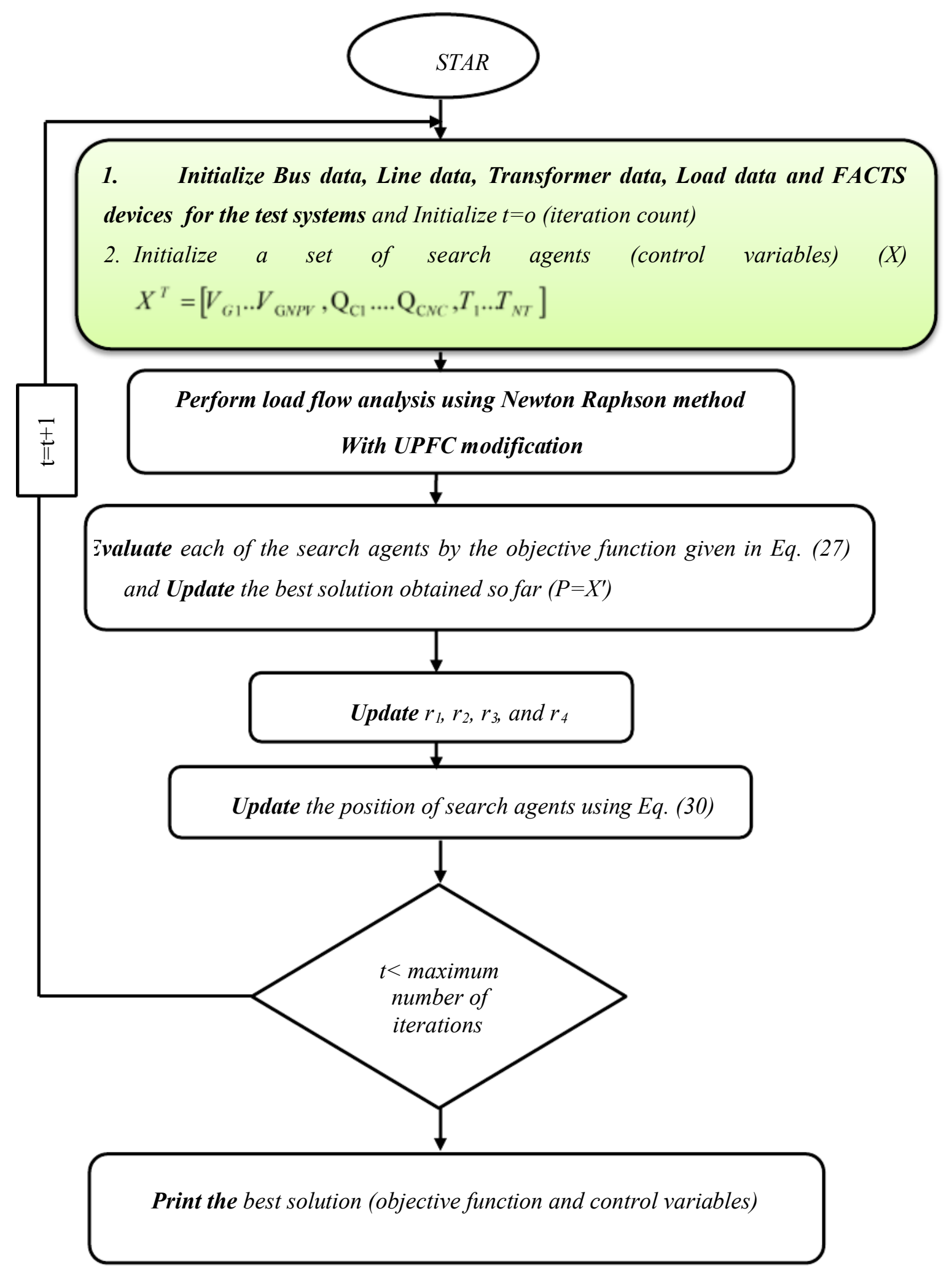

Figure. 6. Flowchart for the solution of the SCA Algorithm for ORPD problem 


\subsection{Implementation of Sine Cosine Optimization Algorithm for ORPD with FACTS devices}

Step1: Initialization the set of search agents (control variables) (X).

$$
X^{T}=\left[V_{G 1} . . V_{\mathrm{GNPV}}, \mathrm{Q}_{\mathrm{Cl}} \ldots \mathrm{Q}_{\mathrm{CNC}}, T_{1} . . T_{N T}\right]
$$

Step 2: Perform Newton Raphson load flow analysis, and ascertain the solution using Eq. (27) for the initialized set of search agents from step 1 .

Step 3: Save the best solutions obtained so far, assigns it as the last point $\left(\mathrm{P}=\mathrm{X}^{\prime}\right)$, and update the other solutions with respect to it.

Step 4: Meanwhile, the ranges of sine and cosine functions $\left(r_{1}, r_{2}, r_{3}\right.$, and $\left.r_{4}\right)$ are updated to emphasize development of the search space as the iteration counter increases

Step 5: Check the termination criteria (In this study, SCA algorithm terminates the optimization process when the iteration counter goes higher than the upper limit number of iterations by default). If its satisfied, publish the best solution (objective function and control variables) else Update the position of search agents using Eq. (30) and goto step 2.

\section{TEST SYSTEMS}

In this paper, sine cosine algorithm is applied to standard IEEE 57 and IEEE 118 test systems for the solution of the conventional ORPD problem. 25 Trial runs were also taken for each of the process and the best results of each process are presented for comparison. The maximum number of iterations was taken 1000, for each case. Single line diagram of all the test systems were given in Fig. 7 and Fig. 8 with its description is depicted in Table 2. Simulations are carried out using MATlab R2015a software [39]. All the necessary details about the test systems were taken from MATPOWER tool box [40].

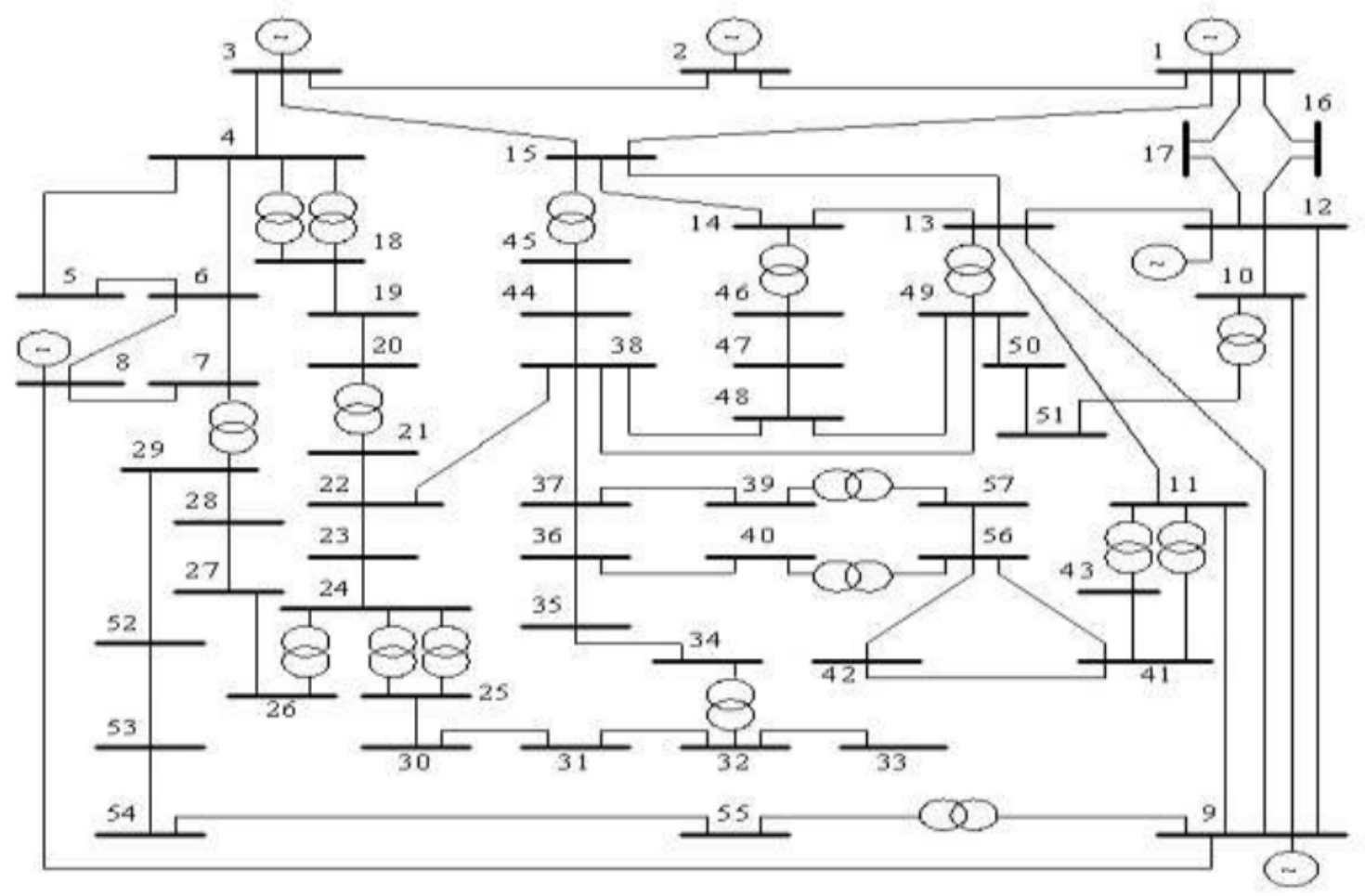

Figure 7. Single line diagram of IEEE-57 bus system 


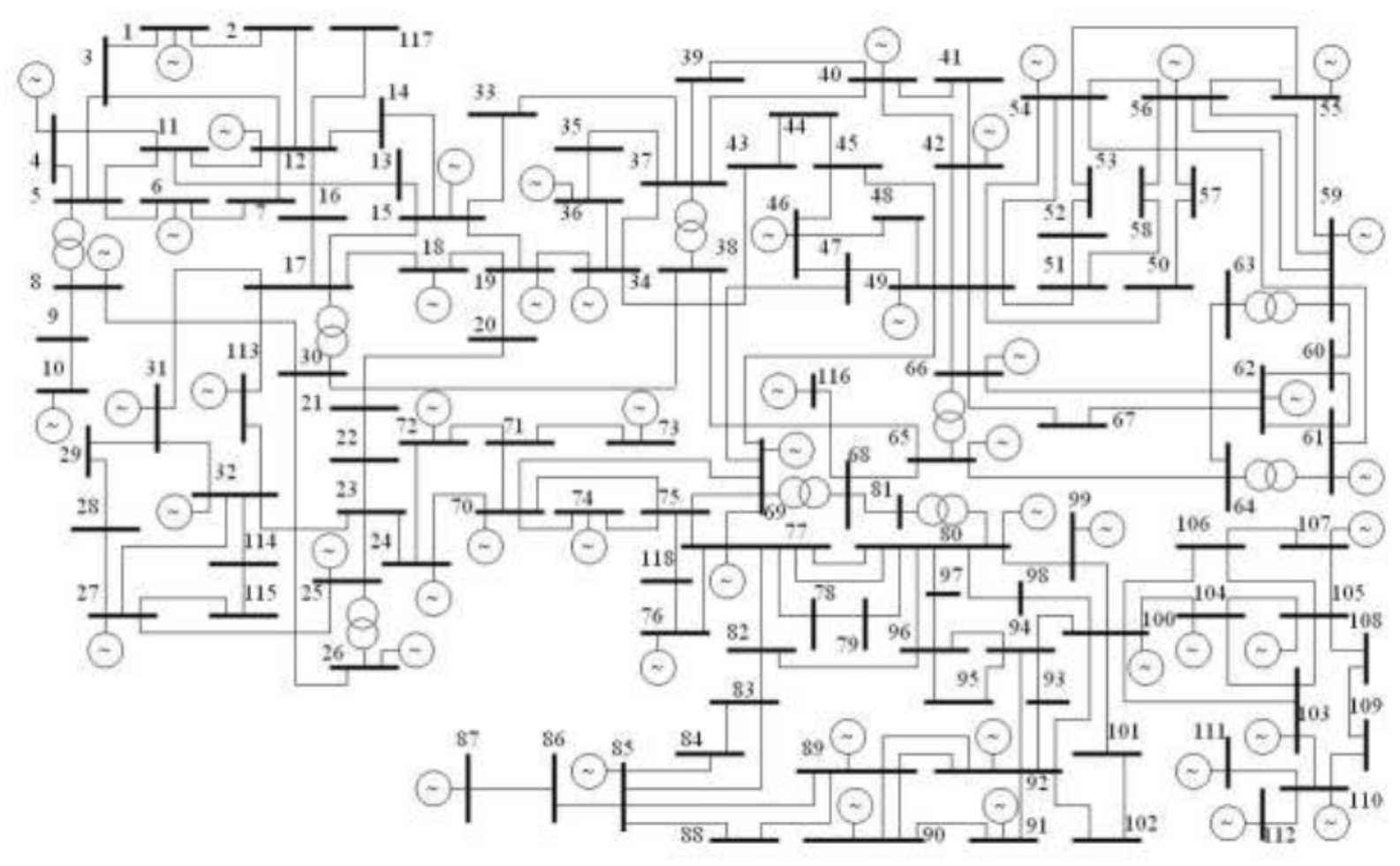

Figure 8. Single line diagram of IEEE-118 bus system

Table 2. Description of test systems - Base case

\begin{tabular}{|l|c|c|}
\hline \multicolumn{1}{|c|}{ Description } & IEEE 57-bus & IEEE 118-bus \\
\hline Buses & 57 & 118 \\
\hline Generators & 7 & 54 \\
\hline Transformers & 15 & 9 \\
\hline Shunts & 3 & 14 \\
\hline Branches & 80 & 186 \\
\hline Control variables & 25 & 77 \\
\hline Base case P Load $_{\text {LW) }}(\mathrm{MW})$ & 1250.80 & 4242 \\
\hline Base case $\mathrm{Q}_{\text {Load }}(\mathrm{MVAr})$ & 336.40 & 1438 \\
\hline
\end{tabular}

\section{RESULTS AND DISCUSSION}

\subsection{Test System 1: Standard IEEE-57 Bus System}

The standard IEEE 57-bus system consists of 80 transmission lines, seven generators at 1, 2, $3,6,8,9,12$ and branches under load tap setting transformer branches. The reactive power sources are viewed as buses 18, 25 and 53. The system line data, bus information, variable limits and the initial values of the control variables were presented in $[12,17,19,23,24]$. The search space of this case system has 22 dimensions, including 7 generator voltages, 15 transformer taps. The upper and lower boundaries of generation reactive power and control variable limits of trial system are given in Table 3. The lower and upper limits of the series voltage sources of the UPFC are taken within the interval of $0-0.2$ p.u., respectively, and the limiting values of the shunt voltage sources of the UPFC are taken in between 0 and 1.1 p.u. The phase angles of these sources are within the range of $0-2 \pi$. The shunt and series impedances of installed UPFC are taken as $(0.01+\mathrm{j} 0.1)$ p.u. and $(0.001+\mathrm{j} 0.2)$ p.u., respectively. The entire system load is $1250.8 \mathrm{MW}$ and 336.4 MVAr. In order to analyze the 
Optimal Reactive Power Dispatch with Series and Shunt Facts Devices using Sine Cosine Algorithm

system under stressed condition, active and reactive power demand of each load bus are multiplied by 1.25 [41].

Table 3. Limits of control variables for IEEE-57 bus system

\begin{tabular}{|c|c|c|c|c|c|c|c|c|c|c|c|c|c|}
\hline \multicolumn{14}{|c|}{ Reactive power sources (pu) } \\
\hline \multicolumn{8}{|c|}{$Q_{C}^{\min }$} & \multicolumn{6}{|c|}{$Q_{C}^{\max }$} \\
\hline Bus No & 1 & 2 & 3 & 6 & 8 & 9 & 12 & \begin{tabular}{l|l}
1 & 2 \\
\end{tabular} & 3 & 6 & 8 & 9 & 12 \\
\hline Values & -1.4 & -0.17 & $|-0.1|$ & -0.08 & -1.4 & -0.03 & -1.5 & \begin{tabular}{|l|l|}
2.0 & 0.50 \\
\end{tabular} & 0.6 & 0.25 & 2.0 & 0.09 & 1.55 \\
\hline \multicolumn{8}{|c|}{ Generator voltages (pu) } & \multicolumn{6}{|c|}{ Transformer taps } \\
\hline \multicolumn{3}{|c|}{$V_{G}^{\min }$} & \multicolumn{5}{|c|}{$V_{G}^{\max }$} & $T_{i}^{\min }$ & & \multicolumn{4}{|c|}{$T_{i}^{\max }$} \\
\hline \multicolumn{3}{|c|}{0.95} & \multicolumn{5}{|c|}{1.1} & 0.9 & & \multicolumn{4}{|c|}{1.1} \\
\hline
\end{tabular}

Table 4. Best control variables settings and active power loss for IEEE 57 bus system (with UPFC)

\begin{tabular}{|c|c|c|c|c|c|}
\hline Control variables & $\begin{array}{c}\text { SCA } \\
\text { (proposed })\end{array}$ & BBO [41] & DE[41] & KHA[41] & OKHA[41] \\
\hline $\mathrm{V}_{I}(\mathrm{pu})$ & 1.1000 & 1.0537 & 1.0440 & 1.0537 & 1.0467 \\
\hline $\mathrm{V}_{2}(\mathrm{pu})$ & 1.1000 & 1.0512 & 1.0316 & 1.0449 & 1.0441 \\
\hline $\mathrm{V}_{3}(\mathrm{pu})$ & 1.0768 & 1.0199 & 1.0210 & 1.0211 & 1.0196 \\
\hline $\mathrm{V}_{6}(\mathrm{pu})$ & 1.0558 & 0.9978 & 0.9983 & 1.0022 & 1.0152 \\
\hline $\mathrm{V}_{8}(\mathrm{pu})$ & 1.0566 & 1.0408 & 1.0358 & 1.0336 & 1.0288 \\
\hline $\mathrm{V}_{9}(\mathrm{pu})$ & 1.0795 & 1.0299 & 1.0359 & 1.0335 & 1.0296 \\
\hline $\left.\mathrm{V}_{12}, \mathrm{pu}\right)$ & 1.1000 & 1.0003 & 1.0023 & 1.0003 & 1.0080 \\
\hline $\mathrm{T}_{4-18}$ & 0.9937 & 1.0036 & 0.9462 & 1.0199 & 0.9181 \\
\hline $\mathrm{T}_{4-18}$ & 1.0765 & 0.9436 & 1.0174 & 0.9591 & 1.0687 \\
\hline $\mathrm{T}_{21-20}$ & 1.0284 & 0.9866 & 0.9781 & 0.9731 & 0.9879 \\
\hline $\mathrm{T}_{24-26}$ & 0.9033 & 1.0836 & 1.0982 & 1.0817 & 1.0937 \\
\hline $\mathrm{T}_{7-29}$ & 0.9998 & 0.9361 & 0.9281 & 0.9361 & 0.9248 \\
\hline $\mathrm{T}_{34-32}$ & 0.9100 & 0.9007 & 0.9006 & 0.9002 & 0.9016 \\
\hline $\mathrm{T}_{11-41}$ & 0.9637 & 0.9062 & 0.9014 & 0.9062 & 0.9172 \\
\hline $\mathrm{T}_{15-45}$ & 1.0515 & 0.9108 & 0.9025 & 0.9108 & 0.9273 \\
\hline $\mathrm{T}_{14-46}$ & 1.0075 & 0.9473 & 0.9498 & 0.9543 & 0.9271 \\
\hline $\mathrm{T}_{10-51}$ & 1.0257 & 0.9832 & 1.0018 & 0.9828 & 0.9904 \\
\hline $\mathrm{T}_{13-49}$ & 1.0141 & 0.9017 & 0.9079 & 0.9017 & 0.9012 \\
\hline $\mathrm{T}_{11-43}$ & 1.0432 & 0.9066 & 0.9195 & 0.9042 & 0.9267 \\
\hline $\mathrm{T}_{40-56}$ & 0.9943 & 1.0617 & 1.0379 & 1.0605 & 1.0161 \\
\hline $\mathrm{T}_{39-57}$ & 0.9753 & 0.9036 & 0.9222 & 0.9188 & 0.9593 \\
\hline $\mathrm{T}_{9-55}$ & 0.9999 & 0.9968 & 1.0100 & 0.9946 & 1.0223 \\
\hline $\mathrm{Q}_{C-18}(\mathrm{pu})$ & 0.0654 & 0.0246 & 0.0618 & 0.0236 & 0.0631 \\
\hline $\mathrm{Q}_{C-25}(\mathrm{pu})$ & 0.0432 & 0.0581 & 0.0585 & 0.0583 & 0.0566 \\
\hline $\mathrm{Q}_{C-53}(\mathrm{pu})$ & 0.4505 & 0.0602 & 0.0581 & 0.0619 & 0.0465 \\
\hline & & & & & \\
\hline
\end{tabular}


Table 5. Best solutions of all algorithms for IEEE 57 bus system.

\begin{tabular}{|l|c|c|c|c|c|}
\hline & $\begin{array}{c}\text { SCA } \\
\text { (proposed) }\end{array}$ & BBO [41] & DE[41] & KHA[41] & OKHA[41] \\
\hline \multicolumn{7}{|c|}{ Active power injected by UPFC (p.u.) } \\
\hline Sending end & 0.0765 & 0.0340 & 0.0718 & 0.0483 & 0.0664 \\
\hline Receiving end & 0.0675 & 0.0387 & 0.0699 & 0.0518 & 0.0684 \\
\hline \multicolumn{5}{|c|}{ Reactive power injected by UPFC (p.u.) } \\
\hline Sending end & 0.0187 & 0.0317 & 0.0813 & 0.0347 & 0.0196 \\
\hline Receiving end & 0.0065 & 0.0293 & 0.0545 & 0.0303 & 0.0082 \\
\hline \multicolumn{7}{|c|}{ Optimal location and parameters of UPFC } \\
\hline Optimal position & $12-16$ & $12-17$ & $19-20$ & $12-17$ & $12-16$ \\
\hline Series source voltage (rad) & 0.0543 & 0.0359 & 0.0611 & 0.0238 & 0.0529 \\
\hline $\begin{array}{l}\text { Series source phase angle } \\
\text { (rad) }\end{array}$ & 0.1432 & 0.0128 & 0.0106 & 0.0333 & 0.1320 \\
\hline Shunt source voltage (p.u.) & 1.0232 & 1.0362 & 1.0271 & 1.0316 & 1.0118 \\
\hline $\begin{array}{l}\text { Shunt source phase angle } \\
\text { (rad) }\end{array}$ & 0.0675 & 0.0916 & 0.0754 & 0.0551 & 0.0782 \\
\hline Loss (MW) & 39.098 & 41.3703 & 41.7006 & 41.0127 & 40.7324 \\
\hline Voltage deviation (p.u.) & 0.0314 & 1.2117 & 1.2067 & 0.9875 & 0.0328 \\
\hline Computational time (s) & 3.987 & 18.0723 & 14.8143 & 4.6327 & 4.1710 \\
\hline
\end{tabular}

A comparison is made among the best compromise solution obtained from the proposed SCA method and the solutions obtained by BBO, DE, KHA and $\mathrm{OKH}$ algorithms. The results of this comparison are shown in Table 4 and 5. As it is shown in Table 5, the results achieve from the presented SCA method for the best transmission loss and voltage deviation are significantly reduced to those of the $\mathrm{BBO}, \mathrm{DE}, \mathrm{KHA}$ and OKHA algorithms which demonstrates the reliability of the SCA algorithm.

\subsection{Test System 2: Standard IEEE-118 Bus System}

To test the proposed technique in solving larger power systems, a standard IEEE 118-bus test system is considered. The search space of this case system has 77 dimensions, that is, the 54 generator buses, 64 load buses, 186 transmission lines, 9 transformer taps and 14 reactive power sources. The system line data, bus data, variable limits and the initial values of control variables were given in $[19,23,25,29]$. The maximum and minimum limits of reactive power sources, voltage and tap-setting limits are given in Tables 6 respectively. The voltage limits of the series sources of the UPFC are taken as 0-0.2 p.u. and the lower and upper limits of the shunt voltage sources of the UPFC are 0 p.u. and 1.1 p.u., respectively. The phase angles of both series and shunt sources are within the range of $0-2 \mathrm{p}$. The shunt and series impedances of installed UPFC are taken as $(0.01+\mathrm{j} 0.1)$ p.u. and $(0.001+\mathrm{j} 0.2)$ p.u., respectively.The system loads are given as follows $\mathrm{P}_{\text {load }}=4242 \mathrm{MW}, \mathrm{Q}_{\text {load }}=1438 \mathrm{MVAr}$.

Table 6. Limits of control variables for IEEE-118 bus system

\begin{tabular}{|c|c|c|c|c|c|c|c|c|c|c|c|c|c|c|}
\hline \multicolumn{15}{|c|}{ Reactive power sources (MVAr) } \\
\hline \multicolumn{8}{|c|}{$Q_{C}^{\text {min }}$} & \multicolumn{7}{|c|}{$Q_{C}^{\max }$} \\
\hline Bus No & 5 & 34 & 37 & 44 & 45 & 46 & 48 & 5 & 34 & 37 & 44 & 45 & 46 & 48 \\
\hline Values & -40 & 0 & -25 & 0 & 0 & 0 & 0 & 0 & 14 & 0 & 10 & 10 & 10 & 15 \\
\hline Bus No & 74 & 79 & 82 & 83 & 105 & 107 & 110 & 74 & 79 & 82 & 83 & 105 & 107 & 110 \\
\hline Values & 0 & 0 & 0 & 0 & 0 & 0 & 0 & 12 & 20 & 20 & 10 & 20 & 6 & 6 \\
\hline \multicolumn{8}{|c|}{ Generator voltages (pu) } & \multicolumn{7}{|c|}{ Transformer tap } \\
\hline \multicolumn{3}{|c|}{$V_{G}^{\min }$} & \multicolumn{5}{|c|}{$V_{G}^{\max }$} & \multicolumn{2}{|c|}{$T_{i}^{\min }$} & \multicolumn{5}{|c|}{$T_{i}^{\max }$} \\
\hline \multicolumn{3}{|c|}{0.95} & \multicolumn{5}{|c|}{1.1} & \multicolumn{2}{|c|}{0.9} & \multicolumn{5}{|c|}{1.1} \\
\hline
\end{tabular}


Optimal Reactive Power Dispatch with Series and Shunt Facts Devices using Sine Cosine Algorithm

Table 7. Best control variables settings for IEEE-118 bus system

\begin{tabular}{|c|c|c|c|c|c|}
\hline Control variables & SCA (proposed) & $B B O$ [41] & $D E[41]$ & $K H A[41]$ & OKHA[41] \\
\hline $\mathrm{V}_{l}(\mathrm{pu})$ & 1.0125 & 0.9944 & 1.0014 & 1.0022 & 0.9944 \\
\hline $\mathrm{V}_{4}(\mathrm{pu})$ & 1.0133 & 1.0223 & 1.0160 & 1.0311 & 1.0244 \\
\hline $\mathrm{V}_{6}(\mathrm{pu})$ & 1.0105 & 0.9918 & 0.9955 & 1.0006 & 1.0108 \\
\hline $\mathrm{V}_{8}(\mathrm{pu})$ & 1.0078 & 1.0169 & 0.9532 & 1.0067 & 1.0855 \\
\hline $\mathrm{V}_{10}(\mathrm{pu})$ & 1.0067 & 0.9791 & 1.0202 & 1.0775 & 1.0998 \\
\hline $\mathrm{V}_{12}(\mathrm{pu})$ & 1.0082 & 1.0037 & 1.0264 & 1.0004 & 1.0091 \\
\hline $\mathrm{V}_{15}(\mathrm{pu})$ & 1.0113 & 0.9747 & 1.0096 & 1.0302 & 1.0198 \\
\hline $\mathrm{V}_{18}(\mathrm{pu})$ & 1.0118 & 0.9952 & 1.0302 & 1.0388 & 1.0168 \\
\hline $\mathrm{V}_{19}(\mathrm{pu})$ & 1.0125 & 1.0102 & 1.0297 & 1.0145 & 1.0155 \\
\hline $\mathrm{V}_{24}(\mathrm{pu})$ & 1.0076 & 1.0602 & 1.0012 & 1.0260 & 1.0338 \\
\hline $\mathrm{V}_{25}(\mathrm{pu})$ & 1.0031 & 1.0154 & 1.0767 & 1.0834 & 1.0937 \\
\hline $\mathrm{V}_{26}(\mathrm{pu})$ & 1.0134 & 1.0106 & 1.0055 & 1.0437 & 1.0977 \\
\hline $\mathrm{V}_{27}(\mathrm{pu})$ & 1.0117 & 1.0293 & 0.9764 & 1.0104 & 1.0430 \\
\hline $\mathrm{V}_{31}(\mathrm{pu})$ & 1.0123 & 0.9936 & 1.0023 & 0.9865 & 1.0238 \\
\hline $\mathrm{V}_{32}(\mathrm{pu})$ & 1.0121 & 0.9865 & 1.0224 & 1.0155 & 1.0343 \\
\hline $\mathrm{V}_{34}(\mathrm{pu})$ & 1.0135 & 1.0288 & 1.0458 & 1.0118 & 1.0136 \\
\hline $\mathrm{V}_{36}(\mathrm{pu})$ & 1.0137 & 0.9804 & 0.9961 & 1.0043 & 1.0081 \\
\hline $\mathrm{V}_{40}(\mathrm{pu})$ & 1.0101 & 1.0186 & 1.0126 & 1.0032 & 1.0065 \\
\hline $\mathrm{V}_{42}(\mathrm{pu})$ & 1.0116 & 0.9725 & 1.0076 & 1.0306 & 1.0185 \\
\hline $\mathrm{V}_{46}(\mathrm{pu})$ & 1.0143 & 1.0117 & 1.0161 & 1.0413 & 1.0355 \\
\hline $\mathrm{V}_{49}(\mathrm{pu})$ & 1.0105 & 1.0060 & 1.0040 & 1.0053 & 1.0457 \\
\hline $\mathrm{V}_{54}(\mathrm{pu})$ & 1.0106 & 1.0153 & 0.9972 & 1.0287 & 1.0090 \\
\hline $\mathrm{V}_{55}(\mathrm{pu})$ & 1.0125 & 1.0581 & 0.9901 & 1.0213 & 1.0149 \\
\hline $\mathrm{V}_{56}(\mathrm{pu})$ & 1.0112 & 1.0381 & 1.0130 & 1.0212 & 1.0128 \\
\hline $\mathrm{V}_{59}(\mathrm{pu})$ & 1.0114 & 1.0572 & 1.0130 & 1.0176 & 1.0300 \\
\hline $\mathrm{V}_{61}(\mathrm{pu})$ & 1.0127 & 0.9726 & 0.9998 & 0.9940 & 1.0078 \\
\hline $\mathrm{V}_{62}(\mathrm{pu})$ & 1.0135 & 0.9757 & 1.0187 & 0.9755 & 1.0193 \\
\hline $\mathrm{V}_{65}(\mathrm{pu})$ & 1.0121 & 0.9931 & 0.9612 & 1.0202 & 1.0637 \\
\hline $\mathrm{V}_{66}(\mathrm{pu})$ & 1.0136 & 1.0366 & 1.0078 & 1.0383 & 1.0629 \\
\hline $\mathrm{V}_{69}(\mathrm{pu})$ & 1.0113 & 1.0452 & 0.9836 & 1.0472 & 1.0621 \\
\hline $\mathrm{V}_{70}(\mathrm{pu})$ & 1.0150 & 0.9853 & 1.0418 & 1.0302 & 1.0178 \\
\hline $\mathrm{V}_{72}(\mathrm{pu})$ & 1.0105 & 0.9528 & 1.0120 & 1.0236 & 1.0165 \\
\hline $\mathrm{V}_{73}(\mathrm{pu})$ & 1.0134 & 1.0137 & 0.9761 & 0.9579 & 1.0161 \\
\hline $\mathrm{V}_{74}(\mathrm{pu})$ & 1.0073 & 0.9603 & 1.0065 & 0.9829 & 1.0052 \\
\hline $\mathrm{V}_{76}(\mathrm{pu})$ & 1.0131 & 1.0323 & 1.0462 & 1.0264 & 0.9893 \\
\hline $\mathrm{V}_{77}(\mathrm{pu})$ & 1.0121 & 1.0193 & 1.0171 & 1.0006 & 1.0068 \\
\hline $\mathrm{V}_{80}(\mathrm{pu})$ & 1.0118 & 1.0416 & 1.0279 & 1.0355 & 1.0267 \\
\hline $\mathrm{V}_{85}(\mathrm{pu})$ & 1.0104 & 1.0092 & 1.0399 & 1.0285 & 1.0451 \\
\hline $\mathrm{V}_{87}(\mathrm{pu})$ & 1.0124 & 1.0005 & 1.0066 & 0.9964 & 1.0263 \\
\hline $\mathrm{V}_{89}(\mathrm{pu})$ & 1.0131 & 1.0155 & 1.0163 & 1.0422 & 1.0955 \\
\hline $\mathrm{V}_{90}(\mathrm{pu})$ & 1.0123 & 1.0484 & 0.9507 & 1.0441 & 1.0662 \\
\hline $\mathrm{V}_{91}(\mathrm{pu})$ & 1.0117 & 1.0085 & 0.9939 & 1.0113 & 1.0603 \\
\hline $\mathrm{V}_{92}(\mathrm{pu})$ & 1.0115 & 0.9929 & 1.0379 & 1.0271 & 1.0708 \\
\hline $\mathrm{V}_{99}(\mathrm{pu})$ & 1.0129 & 0.9589 & 1.0623 & 1.0335 & 1.0572 \\
\hline $\mathrm{V}_{100}(\mathrm{pu})$ & 1.0135 & 1.0353 & 1.0393 & 1.0316 & 1.0717 \\
\hline$V_{103}(\mathrm{pu})$ & 1.0095 & 1.0298 & 1.0493 & 1.0514 & 1.0715 \\
\hline$V_{104}(\mathrm{pu})$ & 1.0120 & 1.0322 & 1.0909 & 1.0121 & 1.0712 \\
\hline $\mathrm{V}_{105}(\mathrm{pu})$ & 1.0134 & 1.0120 & 1.0108 & 0.9901 & 1.0639 \\
\hline $\mathrm{V}_{107}(\mathrm{pu})$ & 1.0090 & 1.0151 & 1.0688 & 1.0350 & 1.0470 \\
\hline $\mathrm{V}_{110}(\mathrm{pu})$ & 1.0131 & 0.9923 & 0.9845 & 1.0076 & 1.0617 \\
\hline $\mathrm{V}_{111}(\mathrm{pu})$ & 1.0131 & 1.0335 & 0.9548 & 1.0505 & 1.0643 \\
\hline $\mathrm{V}_{112}(\mathrm{pu})$ & 1.0100 & 0.9665 & 1.0482 & 0.9990 & 1.0565 \\
\hline $\mathrm{V}_{113}(\mathrm{pu})$ & 1.0094 & 1.0169 & 0.9997 & 1.0167 & 1.0459 \\
\hline $\mathrm{V}_{116}(\mathrm{pu})$ & 1.0127 & 0.9637 & 1.0182 & 0.9655 & 1.0435 \\
\hline $\mathrm{T}_{5-8}$ & 0.9984 & 1.0374 & 1.0238 & 1.0667 & 1.0864 \\
\hline$T_{25-26}$ & 1.0014 & 0.9460 & 1.0712 & 0.9111 & 1.0224 \\
\hline $\mathrm{T}_{17-30}$ & 0.9965 & 0.9608 & 1.0004 & 1.0491 & 1.0192 \\
\hline$T_{37-38}$ & 0.9949 & 0.9717 & 0.9654 & 0.9101 & 0.9696 \\
\hline$T_{59-63}$ & 0.9969 & 1.0211 & 1.0663 & 1.0328 & 1.0315 \\
\hline $\mathrm{T}_{61-64}$ & 0.9751 & 0.9799 & 1.0715 & 0.9469 & 1.0253 \\
\hline
\end{tabular}




\begin{tabular}{|c|c|c|c|c|c|}
\hline$T_{65-66}$ & 0.9856 & 0.9436 & 0.9088 & 0.9549 & 0.9274 \\
\hline$T_{68-69}$ & 1.0010 & 0.9184 & 0.9454 & 0.9218 & 1.0076 \\
\hline $\mathrm{T}_{80-81}$ & 0.9983 & 0.9637 & 1.0182 & 0.9655 & 1.0435 \\
\hline $\mathrm{Q}_{\mathrm{c} 5}(\mathrm{pu})$ & 0.0888 & 0.1246 & 0.2359 & 0.2282 & 0.0988 \\
\hline $\mathrm{Q}_{\mathrm{C} 34}(\mathrm{pu})$ & 0.0127 & 0.0056 & 0.0369 & 0.0211 & 0.0027 \\
\hline $\mathrm{Q}_{\mathrm{c} 37}(\mathrm{pu})$ & 0.0154 & 0.1669 & 0.0685 & 0.1209 & 0.0264 \\
\hline $\mathrm{Q}_{\mathrm{c} 44}(\mathrm{pu})$ & 0.0780 & 0.0747 & 0.0574 & 0.0691 & 0.0790 \\
\hline $\mathrm{Q}_{\mathrm{C} 45}(\mathrm{pu})$ & 0.0968 & 0.0300 & 0.0725 & 0.0901 & 0.0868 \\
\hline $\mathrm{Q}_{\mathrm{c} 46}(\mathrm{pu})$ & 0.0894 & 0.0285 & 0.0765 & 0.0613 & 0.0784 \\
\hline $\mathrm{Q}_{\mathrm{c} 48}(\mathrm{pu})$ & 0.0024 & 0.0313 & 0.0286 & 0.0070 & 0.0037 \\
\hline $\mathrm{Q}_{\mathrm{c} 74}(\mathrm{pu})$ & 0.0205 & 0.0050 & 0.0239 & 0.0749 & 0.0204 \\
\hline $\mathrm{Q}_{\mathrm{c} 79}(\mathrm{pu})$ & 0.1807 & 0.1214 & 0.1392 & 0.1379 & 0.1907 \\
\hline $\mathrm{Q}_{\mathrm{c} 82}(\mathrm{pu})$ & 0.1720 & 0.1633 & 0.1284 & 0.1812 & 0.1910 \\
\hline $\mathrm{Q}_{\mathrm{C} 83}(\mathrm{pu})$ & 0.0580 & 0.0874 & 0.0004 & 0.0693 & 0.0610 \\
\hline $\mathrm{Q}_{\mathrm{c} 105}(\mathrm{pu})$ & 0.1243 & 0.1791 & 0.1602 & 0.1595 & 0.1143 \\
\hline $\mathrm{Q}_{\mathrm{c} 107}(\mathrm{pu})$ & 0.0086 & 0.0036 & 0.0273 & 0.0036 & 0.0066 \\
\hline $\mathrm{Q}_{\mathrm{c} 110}(\mathrm{pu})$ & 0.0013 & 0.0201 & 0.0143 & 0.0400 & 0.0032 \\
\hline
\end{tabular}

Table 8. Best solutions of all algorithms for IEEE 118 bus system.

\begin{tabular}{|l|c|c|c|c|c|}
\hline \multicolumn{7}{|c|}{ SCA (proposed) } & BBO [41] & DE[41] & KHA[41] & OKHA[41] \\
\hline \multicolumn{7}{|c|}{ Active power injected by UPFC (p.u.) } \\
\hline Sending end & 0.0265 & 0.0238 & 0.0417 & 0.0182 & 0.0295 \\
\hline Receiving end & 0.0275 & 0.0226 & 0.0429 & 0.0211 & 0.0284 \\
\hline \multicolumn{7}{|c|}{ Reactive power injected by UPFC (p.u.) } \\
\hline Sending end & 0.0287 & 0.0316 & 0.0206 & 0.0344 & 0.0267 \\
\hline Receiving end & 0.0165 & 0.0284 & 0.0137 & 0.0224 & 0.0230 \\
\hline \multicolumn{7}{|c|}{ Optimal location and parameters of UPFC } \\
\hline Optimal position & $51-58$ & $49-54$ & $50-57$ & $56-58$ & $50-57$ \\
\hline Series source voltage (rad) & 0.0533 & 0.0583 & 0.0982 & 0.0643 & 0.0695 \\
\hline $\begin{array}{l}\text { Series source phase angle } \\
\text { (rad) }\end{array}$ & 0.0432 & 0.0828 & 0.1042 & 0.0837 & 0.0571 \\
\hline Shunt source voltage (p.u.) & 1.0532 & 1.0346 & 1.0283 & 1.0498 & 1.0428 \\
\hline Shunt source phase angle (rad) & 0.0275 & 0.1221 & 0.1006 & 0.0672 & 0.0390 \\
\hline Loss (MW) & 185.987 & 194.3421 & 197.0782 & 192.6608 & 190.3824 \\
\hline Voltage deviation (p.u.) & 1.1877 & 1.2842 & 1.3018 & 1.2715 & 1.1944 \\
\hline Computational time (s) & 7.987 & 22.8240 & 19.7211 & 8.3772 & 8.3069 \\
\hline
\end{tabular}

In order to validate the effectiveness of the proposed procedure for multi-objective problem, it is applied on IEEE 118-bus system to minimize the transmission loss and voltage deviation simultaneously. To validate the superiority, the proposed SCA method is compared with the BBO, DE, KHA and OKHA algorithms. The optimal control variable settings, transmission loss and voltage deviation obtained using various intelligent techniques are given in Table 7. It can be seen from Table 7 that the proposed SCA technique gives the best compromising solutions among all the techniques without violating any operating constraint limits. Moreover, for minimizing the real power losses and voltage deviation further, a UPFC device is optimally placed on IEEE 118-bus system by the presented approaches. Results obtained by the proposed SCA method are compared with OKHA, KHA, BBO and DE methods which are summarized in Table 8 . The simulation results clearly show that the best compromising transmission loss and voltage deviation obtained by the proposed SCA approach is least compared with other methods which emphasizes its better solution quality. 


\section{CONCLUSION}

In the proposed work, Sine Cosine optimization algorithm is applied for effective coordination of UPFC device with the control variables present in a connected power system. To obtain reactive power optimization with FACTS devices, the implementation of sine cosine algorithm has been carried out on the IEEE 57-bus, and large118-bus systems. SCA was one among various optimization methods that produces better results compared with existing literatures. Maintenance of voltage profile, reduction of power loss, and optimization of reactive power have been facilitated by the algorithm. Hence SCA may be considered as a very good optimization technique in the area of power system planning and future research credentials.

\section{REFERENCES}

[1] Dommel, H. W. and Tinney, W. F., Optimal Power Flow Solutions. IEEE Transactions on Power Apparatus and Systems, 1968, 87, 1866-1876.

[2] Venikov, V A Cybernetics in Electrical Power Systems, M I R Publishers, Moscow, 1978.

[3] Mamandur, K R C and Chenoweth, R D 'Optimal Control for Reactive Power Flow for Improvements in Voltage Profiles and for Real Power Losses Minimization', IEEE Transactions on Power Apparatus and Systems PAS-100 (1981) pp 3185-3193.

[4] Deeb N, Shahedipour SM. Linear Reactive Power Optimization in a Large Power Network Using the Decomposition Approach. In: IEEE Tran Power Syst, vol. 5, no. 2; 1990. p. 428-35.

[5] Momoh JA, El-Hawary ME, Adapa R. A Review of Selected Optimal Power Flow Literature to 1993. II. Newton, Linear Programming And Interior Point Methods. IEEE Trans Power Syst 1999;14(1):105-11.

[6] Granville S. Optimal Reactive Dispatch through Interior Point Methods. In: IEEE trans power syst, vol. 9, no. 1; 1994. p. 136-46.

[7] Momoh JA, Adapa R, El-Hawary ME. A Review of Selected Optimal Power Flow Literature to 1993. I. Nonlinear and Quadratic Programming Approaches. IEEE Trans Power Syst 1999;14(1):96-104.

[8] Yan, W., Lu, S., Yu, D.C., 2004. A Novel Optimal Reactive Power Dispatch Method Based on an Improved Hybrid Evolutionary Programming Technique. IEEE Trans. Power Syst. 19 (2), 913-918.

[9] Zhao, B., Guo, C.X., Cao, Y.J., 2005. A Multi-Agent-Based Particle Swarm Optimization Approach For Optimal Reactive Power Dispatch. IEEE Trans. Power Syst. 20 (2), 10701078.

[10] Varadarajan, M., Swarup, K.S., 2008. Differential Evolution Approach for Optimal Reactive Power Dispatch. Applied Soft Computing, 8(4), September 2008, 1549-1561.

[11] Ying Li, Yijia Cao, Zhaoyan Liu, Yi Liu, Quanyuan Jiang., 2009. Dynamic optimal reactive power dispatch based on parallel particle swarm optimization algorithm. Computers and Mathematics with Applications, 57, 1835-1842.

[12] Chaohua Daia,Weirong Chen, Yunfang Zhu, Xuexia Zhang., 2009. Reactive Power Dispatch Considering Voltage Stability with Seeker Optimization Algorithm. Electric Power Systems Research, 79, 1462-1471.

[13] K. Mahadevan, P.S. Kannan., 2010. Comprehensive Learning Particle Swarm Optimization for Reactive Power Dispatch. Applied Soft Computing, 10, 641-652. 
[14] Xuexia Zhang, Weirong Chen, Chaohua Dai, Wenzhao Cai., 2010. Dynamic Multi-Group Self-Adaptive Differential Evolution Algorithm for Reactive Power Optimization. Electrical Power and Energy Systems, 32, 351-357.

[15] A.H. Khazali, M. Kalantar., 2011. Optimal Reactive Power Dispatch Based On Harmony Search Algorithm. Electrical Power and Energy Systems, 33, 684-692.

[16] S. Jeyadevi, S. Baskar, C.K. Babulal, M. Willjuice Iruthayarajan, 2011. Solving Multiobjective Optimal Reactive Power Dispatch Using modified NSGA-II. Electrical Power and Energy Systems, 33, 219-228.

[17] Roy, P.K., Mandal, B., Bhattacharya, K., 2012. Gravitational Search Algorithm Based Optimal Reactive Power Dispatch For Voltage Stability Enhancement. Electr. Power Compon. Syst 40 (9), 956-976.

[18] Xu, Y., Zhang, W., Liu, W., Ferrese, F., 2012. Multiagent-Based Reinforcement Learning for Optimal Reactive Power Dispatch. IEEE Trans. Syst. Man Cybern. Part B Cybern. 42 (6), 1742-1751.

[19] S. Duman., Y. Sonmez., U. Guvenc. , N. Yorukeren, 2012. Optimal Reactive Power Dispatch Using a Gravitational Search Algorithm. IET Gener. Transm. Distrib., Vol. 6, Iss. 6, pp. 563-576

[20] R. Mallipeddi, S. Jeyadevi, P.N. Suganthan, S. Baskar, 2012. Efficient Constraint Handling for Optimal Reactive Power Dispatch Problems. Electrical Power and Energy Systems, 5, 28-36.

[21] Barun Mandal, Provas Kumar Roy, 2013. Optimal Reactive Power Dispatch Using QuasiOppositional Teaching Learning Based Optimization. Electrical Power and Energy Systems, 53, 123-134.

[22] Barun Mandal, Provas Kumar Roy, 2013. Multi-Objective Optimal Reactive Power Dispatch Considering Voltage Stability in Power Systems using HFMOEA. Engineering Applications of Artificial Intelligence, 26, 390-404.

[23] Mojtaba Ghasemi, Sahand Ghavidel, Mohammad Mehdi Ghanbarian, Amir Habibi, 2014. A New Hybrid Algorithm for Optimal Reactive Power Dispatch Problem with Discrete And Continuous Control Variables. Applied Soft Computing 22, 126-140.

[24] Binod Shaw, V. Mukherjee, S.P. Ghoshal, 2014. Solution of Reactive Power Dispatch of Power Systems by an Opposition-Based Gravitational Search Algorithm. Electrical Power and Energy Systems, 55, 29-40.

[25] Abhishek Rajan, T. Malakar, 2015. Optimal Reactive Power Dispatch Using Hybrid Nelder-Mead Simplex Based Firefly Algorithm. Electrical Power and Energy Systems, 66, 9-24.

[26] Mojtaba Ghasemi, Mahdi Taghizadeh, Sahand Ghavidel, Jamshid Aghaei, Abbas Abbasian, 2015. Solving Optimal Reactive Power Dispatch Problem Using a Novel Teaching-Learning-Based Optimization Algorithm. Electrical Power and Energy Systems, 39, 100-108.

[27] Mehdi Mehdinejad, Behnam Mohammadi-Ivatloo, Reza Dadashzadeh-Bonab, Kazem Zare, 2016. Solution of Optimal Reactive Power Dispatch of Power Systems Using Hybrid Particle Swarm Optimization and Imperialist Competitive Algorithms. Electrical Power and Energy Systems, 83, 104-116.

[28] Chandragupta Mauryan Kuppamuthu Sivalingam, Subramanian Ramachandran, Purrnimaa Shiva Sakthi Rajamani, 2017. Reactive Power Optimization In A Power System Network Through Metaheuristic Algorithms. Turk J Elec Eng \& Comp Sci,25, 4615-4623. 
[29] Kasem Nuaekaew, PraminArtrit, Nantiwat Pholdee, Sujin Bureerat, 2017. Optimal Reactive Power Dispatch Problem Using A Two-Archive Multi-Objective Grey Wolf Optimizer. Expert Systems with Applications, 87(30), 79-89.

[30] Xiaoshun Zhang, Tao Yu, Bo Yang, Lefeng Cheng, 2017. Accelerating Bio-Inspired Optimizer with Transfer Reinforcement Learning for Reactive Power Optimization. Knowledge-Based Systems, 116, 26-38.

[31] Khaled ben oualid Medania, Samir Sayaha Abdelghani Bekrarb, 2018. Whale Optimization Algorithm Based Optimal Reactive Power Dispatch: A case study of the Algerian Power System. Electric Power Systems Research, 163, Part B, 696-705.

[32] SK. Mahammad Shareef, R. Srinivasa Rao, 2018. Optimal Reactive Power Dispatch Under Unbalanced Conditions Using Hybrid Swarm Intelligence. Computers and Electrical Engineering, 69,183-193.

[33] Hotaka Yoshida, Yoshikazu Fukuyama, 2018. Parallel Multipopulation Differential Evolutionary Particle Swarm Optimization for Voltage and Reactive Power Control. Electrical Engineering in Japan, Vol. 204, No. 3, 31-40.

[34] Mirjalili S. SCA: A Sine Cosine Algorithm for Solving Optimization Problems. Knowledge Based Systems 2016; 96:120-33.

[35] D. Karthikaikannan, G. Ravi, 2018. Optimal Reactive Power Dispatch Considering MultiType FACTS Devices Using Harmony Search Algorithms, Automatika, 59:3, 303-314.

[36] Hingorani NG. High Power Electronics and Flexible AC Transmission System. IEEE Power Eng Rev 1998

[37] Padhy NP, Abdel Moamen MA. Power Flow Control and Solutions With Multiple and Multi-Type FACTS Devices. Electric Power Syst Res 2005; EPSR-74. 341-35.

[38] Ghahremani E, Kamwa I. Optimal Placement of Multiple-Type FACTS Devices to Maximize Power System Loadability using a Generic Graphical user Interface. IEEE Trans Power Syst 2013;28(2):764-78

[39] MATLAB Release R2015b. Natick (MA, USA): The Mathworks Inc.

[40] Zimmerman RD, Murillo-S'anchez CE. MATPOWER, a MATLAB Power System Simulation Package.<http://www.pserc.cornell.edu/matpower/manual.pdf $>$; September 2007.

[41] Susanta Dutta, Pranabesh Mukhopadhyay, Provas Kumar Roy, Debashis Nandi, 2016. Unified Power Flow Controller Based Reactive Power Dispatch Using Oppositional Krill Herd Algorithm. Electrical Power and Energy Systems, 80, 10-25.

[42] Sarabjeet Singh, Satvir Singhand Vijay Kumar Banga, GPU Based Toolbox for Fuzzy Logic System using Whale Optimization Algorithm. International Journal of Computer Engineering and Technology,10(1), 2019, pp. 11-24

[43] Smitkumar Choudante and A.A. Bhole, Comparision of Voltage Stability and Power Flow Improvement by using Different Facts Devices: International Journal of Electrical Engineering \& Technology, 9(4), 2018, pp. 144-153

[44] Radhakrishna K R, Dr. T Ananthapadmanabha, Likith Kumar M V and R. Chidanandappa, Minimization of Losses in Distribution System with D-Facts Devices. International Journal of Electrical Engineering \& Technology, 7(4), 2016, pp. 1-15 